\title{
Cost-effectiveness analysis of memantine for moderate-to-severe Alzheimer's disease in the Netherlands
}

This article was published in the following Dove Press journal:

Neuropsychiatric Disease and Treatment

3I May 20I I

Number of times this article has been viewed

Bart Hoogveldt'

Benoît Rive ${ }^{2}$

Johan Severens ${ }^{3}$

Khaled Maman ${ }^{4}$

Chantal Guilhaume ${ }^{5}$

'Field Product Management, Lundbeck BV, Amsterdam, The Netherlands; ${ }^{2}$ Global Outcomes Research, Lundbeck SAS, Issy-les-Moulineaux, France; ${ }^{3}$ Institute of Health Policy and Management, Erasmus University Rotterdam, The Netherlands; ${ }^{4}$ Creativ Research SAS, Paris, France; ${ }^{5} \mathrm{Global}$ Evidence and Value Development, Sanofi-Aventis, Paris, France
Correspondence: Benoît Rive Lundbeck SAS, 43-45 Quai du Président Roosevelt, 92445 Issy-les-

Moulineaux Cedex, France

Tel +33179412912

$\mathrm{Fax}+33|794| 2908$

Email berv@lundbeck.com
Objective: The purpose of this study was to estimate the cost-effectiveness of memantine relative to standard care in patients with moderate-to-severe Alzheimer's disease in the Netherlands.

Methods: A country-adapted five-year Markov model simulated disease progression through a series of states, defined by dependency and disease severity. Transition probabilities were derived from trials, with utility and epidemiological data obtained from a longitudinal Dutch cohort. Cost-effectiveness was described in terms of quality-adjusted life years and time spent in a nondependent state or in a moderate severity state.

Results: Memantine monotherapy versus standard care led to 0.058 quality-adjusted life years gained (1.207 versus 1.265), longer time in a nondependent state (from 1.602 to 1.751 years) and in a moderate state (from 2.051 to 2.141 years), and no additional costs (€113,927 versus $€ 110,097)$. Robustness of results was confirmed through sensitivity analyses.

Conclusion: Memantine is dominant compared with standard care in the Netherlands. Results are consistent with similar economic evaluations in other countries.

Keywords: memantine, Alzheimer's disease, cost-effectiveness analysis, Netherlands, cholinesterase inhibitors

\section{Introduction}

Alzheimer's disease is the most common cause of dementia, accounting for two-thirds of all dementia cases. People with Alzheimer's disease experience gradual loss of independence, and as Alzheimer's disease becomes more severe, the burden on informal caregivers increases until institutionalization is required. A study in the Netherlands showed that dementia patients spend approximately $20-25 \%$ of their time institutionalized with the condition. ${ }^{1}$

Previous pharmacoeconomic studies conducted in the Netherlands have investigated galantamine, an acetylcholinesterase inhibitor, for mild-to-moderate Alzheimer's disease and the general costs associated with the disease. ${ }^{2,3}$

Memantine is a moderate-affinity, noncompetitive N-methyl-D-aspartate antagonist, and is approved in over 70 countries worldwide for the symptomatic treatment of patients with moderate-to-severe Alzheimer's disease. Memantine may be administered as monotherapy or in combination with an acetylcholinesterase inhibitor. In this study, a Markov model was used to determine the cost-effectiveness of memantine relative to standard care in moderate-to-severe Alzheimer's disease in the Netherlands. 


\section{Methods}

This cost-effectiveness study evaluated the five-year outcomes associated with memantine monotherapy compared with no pharmacological treatment (standard care) in terms of additional time living independently, additional time in a moderate state, quality-adjusted life years, and societal costs. A Markov model adapted from a previous model constructed for the Canadian setting was used, and full methodological details are provided in Gagnon et al. ${ }^{4}$ The methods employed here are identical to the Canadian model unless explicitly stated otherwise. Key changes are the data source for the initial patient distribution, background mortality, cost per health state, and discount rates. Each of these inputs was adjusted to make the model directly relevant to the economic assessment of memantine in the Netherlands as described by the College Voor Zorgverzekeringen (CVZ). ${ }^{5}$

\section{Model structure}

In this model, health states were based on dependence and Alzheimer's disease severity, ie, a patient could be in one of five possible states: moderate, independent; moderate, dependent; severe, independent; severe, dependent; death. A six-month Markov cycle was chosen and repeated 10 times.

\section{Perspective}

This study was performed from a societal perspective, with nonmedical costs included, in line with the CVZ guidelines for pharmacoeconomic research.

\section{Data sources}

The initial patient distributions between Markov health states were computed from the Rotterdam study. ${ }^{6}$ This was a large study testing 7528 residents (2939 men and 4589 women) aged 55 years and over (median age 69 years) of a Rotterdam suburb for disorders associated with dementia. The Rotterdam study found a subset of 339 patients diagnosed with Alzheimer's disease, from which the health state distributions were calculated. ${ }^{7}$ The percentages of patients by severity stage and level of dependency were: moderate severity, independent (69.02\%); moderate, dependent (20.11\%); severe, independent (6.52\%); and severe, dependent (4.35\%).

All severity and dependency transition probabilities were assumed to depend only on patient severity and dependency stages at the beginning of the cycle and on treatment, and were estimated using pooled data from four six-month, double-blind, randomized, placebo-controlled clinical trials for memantine considering a total of 1096 patients with moderate-to-severe Alzheimer's disease (589 receiving memantine and 507 receiving placebo). ${ }^{8-11}$ The efficacy of memantine was assumed to last for the first 12 months of treatment, as suggested by an open-label extension study. ${ }^{12}$

Probability of death over each six-month cycle was assumed to be the same for all Markov health states and treatment strategies, and was computed from published Dutch data. ${ }^{3}$ This resulted in an estimated probability of death of $7.55 \%$ for each six-month period when data were adjusted using the weighted mean of probabilities. This was based on the aforementioned initial model distribution for dependency status and an assumption (based on expert opinion) that, for patients in an institution, the split between patients living in a home for the elderly and patients living in a nursing home was $2 / 3: 1 / 3$ in independent patients and $1 / 2: 1 / 2$ in dependent patients. The uncertainty surrounding these parameters was modeled using a priori triangular distributions.

The costs per unit of care were derived from the Dutch guidelines. ${ }^{13}$ The number of units used per health state was estimated from a Dutch model of cost of care for patients with dementia. ${ }^{14}$ The costs of care and consumption by dependency and type of accommodation were calculated in Euros ( $€$, value 1999, Table 1). Because no distinction between genders was made in this study, it was assumed when calculating total cost per stage that approximately $66 \%$ of the patients with Alzheimer's disease were female, based on dementia prevalence estimates among men and women from the Rotterdam study. ${ }^{6}$

The distribution of moderate and severe Alzheimer's disease patients in the Rotterdam study and the split between patients living in a home for the elderly and patients living in a nursing home were applied to costs per dependency and accomodation (Table 1), to compute the costs per Markov health state. Costs were updated to 2008 using the consumer price data from Statistics Netherlands restricted to the health sector. Final six-month cost estimates per Markov health state were 8,092.12 (EUR, 2008) for moderate independent patients, 26,202.87 for moderate dependent, 9,475.97 for severe independent and 27,022.75 for severe dependent. The price used for memantine in the Netherlands was $€ 2.95$ per defined-daily-dose of $20 \mathrm{mg}$. An additional pharmacist fee of $€ 6.10$ per prescription was added. The cost of the memantine treatment over a cycle was $€ 537.10$.

Level of dependency and residential status appear to be the main criteria influencing quality-adjusted life years values, and thus values were taken from the LASER-AD study from the UK that considered 224 Alzheimer's disease 
Table I Annual costs and consumption (€, value 1999) by dependency and accommodation

\begin{tabular}{|c|c|c|c|c|c|}
\hline Stage & Accommodation & Type of care & Costs/unit* & Units $^{\dagger}$ & Costs \\
\hline \multirow[t]{11}{*}{ Independent } & Community & General practitioner & I6.59 Euro/consult & 6.09 consults & I0I.03 Euro \\
\hline & & Family care & I7.70 Euro/hour & 93.59 hours & I656.54 Euro \\
\hline & & District-nursing & 31.76 Euro/hour & $17.5 \mid$ hours & 556.12 Euro \\
\hline & & RIAGG & I02.55 Euro/contact & - & - \\
\hline & & Hospital admission' & 283.84 Euro/day & - & - \\
\hline & & Day-care center & 52.18 Euro/day & - & - \\
\hline & & (including travelling costs) & & & \\
\hline & & Informal care & 7.94 Euro/hour & 260 hours & 2064.40 Euro \\
\hline & & Total & - & - & 4378.09 Euro \\
\hline & Home for the elderly ${ }^{2}$ & Total & 30.33 Euro/day & 365 days & I I 070.45 Euro \\
\hline & Nursing home ${ }^{2}$ & Total & 99.43 Euro/day ${ }^{3}$ & 365 days & 36291.95 Euro \\
\hline \multirow[t]{11}{*}{ Dependent } & Community & General practitioner & 16.59 Euro/hour & 6.09 consults & 101.03 Euro \\
\hline & & Family care & I7.70 Euro/hour & I 83.22 hours & 3242.99 Euro \\
\hline & & District nursing & 31.76 Euro/hour & 213.53 hours & 678I.7I Euro \\
\hline & & RIAGG & I02.55 Euro/contact & 9.4 contacts & 963.97 Euro \\
\hline & & Hospital admission & 283.84 Euro/day & 41.65 days & II82I.94 Euro \\
\hline & & Day-care center & 52.18 Euro/day & 92 days & 4800.56 Euro \\
\hline & & (including travelling costs) & & & \\
\hline & & Informal care & 7.94 Euro/hour & 322 hours & 2556.68 Euro \\
\hline & & Total & - & - & 30268.88 Euro \\
\hline & Home for the elderly ${ }^{2}$ & Total & 94.01 Euro/day & 365 days & 34313.65 Euro \\
\hline & Nursing home ${ }^{2}$ & Total & 171.02 Euro/day $^{3}$ & 365 days & 62422.30 Euro \\
\hline
\end{tabular}

Notes: 'Mean academic and general hospital; ${ }^{2}$ These do not include housing costs; ${ }^{3}$ Mean psychogeriatric and combined nursing homes; *Derived from Oostenbrink et al; ${ }^{13}$ tDerived from Van der Roer. ${ }^{14}$

Abbreviation: RIAGG, regional institutes for mental health.

patients (independent in community, 0.608 [standard error (SE) 0.028]; independent in institution, 0.543 [SE 0.064]; dependent in community. 0.340 [SE 0.058]; dependent in institution, 0.169 [SE 0.058]). ${ }^{15}$

Following Dutch guidelines, health outcomes were discounted at an annual rate of $1.5 \%$, and costs outcomes at $4 \%$.

\section{Analyses}

The base-case scenario reported the mean number of years of independence and moderate severity state, quality-adjusted life years and average costs over five years. Probabilistic analyses using Monte-Carlo simulations comprised of 10,000 draws were conducted, which attributed a value for each of the a priori distributions. The a priori distributions were beta distributions for severity and dependency transition probabilities, log-normal for the odds ratios measuring impact of memantine on severity and dependency transitions, normal distributions for utilities per health states, triangular for the nursing home/ home for elderly proportions, and triangular $( \pm 20 \%)$ for costs per health states. A worst-case scenario was included whereby it was assumed that patients received treatment for two years, but the treatment effect only lasted for six months. One-way sensitivity analyses were conducted on the odds ratios of memantine applied to dependency and severity probabilities. A sensitivity analysis was also conducted on the discount rates (applied to both costs and health benefits) by using the values $0 \%$ and $7 \%$ per annum in the model. Finally, a sensitivity analysis was conducted on the nursing home/home for elderly distributions.

\section{Results}

Compared with the standard care strategy, over five years memantine treatment produced an additional 0.149 years (54.39 days, $95 \%$ credible intervals $[\mathrm{Crl}]=0.036 ; 0.252)$ of independence, 0.091 years $(33.22$ days, $95 \% \mathrm{Crl}=-0.027$; $0.197)$ in the moderate disease state, and $0.058(95 \%$ $\mathrm{Crl}=0.014 ; 0.108)$ additional quality-adjusted life years (Table 2). Furthermore, memantine treatment was associated with a cost reduction of $€ 3,830$ compared with standard care. Memantine was the dominant strategy being more effective and less costly than standard care. There was a $96.8 \%$ probability of memantine being dominant.

Results were robust to sensitivity analyses. For the worstcase scenario, the memantine strategy was associated with an additional 0.078 years $(28.47$ days; $95 \% \mathrm{Crl}=0.019$; 0.132 ) of independence, 0.048 years (17.52 days; $95 \%$ $\mathrm{Crl}=-0.015 ; 0.104)$ in the moderate disease state, and 0.031 additional quality-adjusted life years $(95 \% \mathrm{Crl}=0.007$; 0.057). Memantine was associated with a cost reduction of $€ 920$ over the five-year evaluation period compared with 
Table 2 The cost-effectiveness model outcomes of memantine compared with standard care

\begin{tabular}{|c|c|c|c|c|}
\hline & \multicolumn{2}{|c|}{ Memantine } & \multicolumn{2}{|c|}{ Standard care } \\
\hline & Mean & $2.5 \% ; 97.5 \% \mathrm{Crl}$ & Mean & $2.5 \% ; 97.5 \% \mathrm{Crl}$ \\
\hline \multicolumn{5}{|c|}{ Distribution of model outcomes and costs per strategy } \\
\hline QALYs & 1.265 & $0.999 ; 1.527$ & 1.207 & $0.940 ; 1.471$ \\
\hline Years in independent state & 1.751 & $1.463 ; 2.039$ & 1.602 & $1.335 ; 1.878$ \\
\hline Years in moderate state & 2.141 & $1.852 ; 2.415$ & 2.051 & $1.780 ; 2.322$ \\
\hline Costs $(€$, value 2006$)$ & 110,097 & 96,$599 ; 124,223$ & 113,927 & 100,$364 ; 128,146$ \\
\hline \multicolumn{5}{|c|}{ Distribution of incremental model outcomes and costs associated with memantine } \\
\hline QALYs & 0.058 & $0.014 ; 0.108$ & & \\
\hline Years in independent state & 0.149 & $0.036 ; 0.252$ & & \\
\hline Years in moderate state & 0.091 & $-0.027 ; 0.197$ & & \\
\hline Costs (€, value 2006$)$ & $-3,830$ & $-7,793 ; 208$ & & \\
\hline
\end{tabular}

Abbreviations: Crl, credible interval; QALYs, quality-adjusted life years.

standard care. The probability of memantine being dominant was $80.7 \%$ in this scenario.

\section{Discussion}

This study has shown that over a five-year period in a Dutch setting, compared with standard care in patients with moderate-to-severe Alzheimer's disease, memantine was associated with additional quality-adjusted life years, prolonged time of independence and prolonged time in the moderate Alzheimer's disease state.

These health benefits translated into cost savings, which fully offset the drug cost, making memantine the dominant option. The internal validity and robustness of the model were ensured through numerous sensitivity analyses conducted around key parameters. A major assumption is that the structure of the Canadian model and several inputs are considered generalizable without transferability adaptation. ${ }^{16}$

This study confirmed results from previous costeffectiveness analyses performed in other countries such as the UK, Finland, Norway, Sweden, Spain, and Canada. In each of these evaluations, the additional cost of memantine was offset by health benefits which translated into cost savings. Results were consistent, despite differences in model design, perspective, data sources, geographical location, and time horizon. The estimated gain in terms of months of independence (increase of $9.3 \%$ for 1.8 months) in this study was similar to other evaluations of memantine. Although not directly comparable, it is interesting to note that in an analysis of galantamine for Alzheimer's disease in a number of countries (including the Netherlands), galantamine delayed time to fulltime care by $6.8 \% .{ }^{17}$ As with all pharmacoeconomic analyses, this cost-effectiveness evaluation is subject to a number of limitations because it extrapolates data from the clinical trial setting to model real-life practice and is associated with a number of assumptions.

\section{Conclusion}

This analysis demonstrated that memantine monotherapy produced health benefits compared with standard care which translated into cost savings. Memantine was associated with additional quality-adjusted life years and an extended period of nondependence. These results for the Netherlands are consistent with economic evaluations of memantine in Canada and a number of other countries in Europe.

\section{Acknowledgment}

The authors thank Monique Breteler of Erasmus MC, University Medical Center Rotterdam, Rotterdam, The Netherlands, for her contribution to this research.

\section{Disclosure}

Chantal Guilhaume was an employee of H Lundbeck A/S at the time the analysis was conducted. Otherwise, the authors report no conflicts of interest in this work.

\section{References}

1. Perenboom RJ, Boshuizen HC, Breteler MM, Ott A, Van de Water HP. Dementia-free life expectancy (DemFLE) in The Netherlands. Soc Sci Med. 1996;43:1703-1707.

2. Caro JJ, Salas M, Ward A, Getsios D, Mehnert A. Economic analysis of galantamine, a cholinesterase inhibitor, in the treatment of patients with mild to moderate Alzheimer's disease in the Netherlands. Dement Geriatr Cogn Disord. 2002;14:84-89.

3. McDonnell J, Redekop WK, Van der Roer N, et al. The cost of treatment of Alzheimer's disease in The Netherlands: A regression-based simulation model. Pharmacoeconomics. 2001;19:379-390.

4. Gagnon M, Rive B, Hux M, Guilhaume C. Cost-effectiveness of memantine compared with standard care in moderate-to-severe Alzheimer disease in Canada. Can J Psychiatry. 2007;52:519-526.

5. College voor Zorgverzekeringen. Guidelines for Pharmacoeconomic Research, Updated Version. Diemen, The Netherlands: College voor Zorgverzekeringen; 2006.

6. Breteler MM. A community-based study of dementia: The Rotterdam Elderly Study. Neuroepidemiology. 1992;11 Suppl 1:S23-S28.

7. Ott A, Breteler M, Van Harskamp F, et al. Prevalence of Alzheimer's disease and vascular dementia: Association with education. The Rotterdam study. BMJ. 1995;310:970-973. 
8. Reisberg B, Doody R, Stöffler A, Schmitt F, Ferris S, Möbius HJ. Memantine in moderate-to-severe Alzheimer's disease. $N$ Engl J Med. 2003;348:1333-1341.

9. Peskind ER, Potkin SG, Pomara N, et al. Memantine treatment in mild to moderate Alzheimer disease: A 24-week randomized controlled trial. Am J Geriatr Psychiatry. 2006;14:704-715.

10. Bakchine S, Pascual-Gangnant L, Loft H. Results of a randomised, placebo-controlled 6-month study of memantine in the treatment of mild to moderate Alzheimer's disease in Europe. Abstract presented at the Ninth Congress of the European Federation of the Neurological Societies (EFNS), September 17-20, 2005, Athens, Greece.

11. Van Dyck CH, Tariot PN, Meyers B, Malca Resnick E. A 24-week randomized, controlled trial of memantine in patients with moderateto-severe Alzheimer disease. Alzheimer Dis Assoc Disord. 2007;21 136-143.

12. Reisberg B, Doody R, Stoffler A, Schmitt F, Ferris S, Mobius HJ. A 24-week open-label extension study of memantine in moderate to severe Alzheimer disease. Arch Neurol. 2006;63:49-54.
13. Oostenbrink JB, Koopmanschap MA, Rutten FFH. Handleiding voor Kostenonderzoek. Amstelveen, The Netherlands: College voor Zorgverzekeringen; 2000.

14. Van der Roer N. Model of costs of care for dementia: communitydwelling vs institutionalization. Tijdschr Gerontol Geriatr. 2000;31: 55-61. Dutch.

15. Sapin C, Livingston G, Katona C. Main factors influencing preferencebased utility values in Alzheimer's disease: Results from the LASER-AD Study. Poster presented at the Seventh International Conference on Alzheimer's and Parkinson's Disease (AD/PD), March 9-13, 2005, Sorrento, Italy.

16. Drummond M, Barbieri M, Cook J, et al. Transferability of economic evaluations across jurisdictions: ISPOR Good Research Practices Task Force report. Value Health. 2009;12:409-418.

17. Caro J, Salas M, Ward A, Getsios D, Migliaccio-Walle K, Garfield F. Assessing the health and economic impact of galantamine treatment in patients with Alzheimer's disease in the health care systems of different countries. Drugs Aging. 2004;21:677-686.
Neuropsychiatric Disease and Treatment

\section{Publish your work in this journal}

Neuropsychiatric Disease and Treatment is an international, peerreviewed journal of clinical therapeutics and pharmacology focusing on concise rapid reporting of clinical or pre-clinical studies on a range of neuropsychiatric and neurological disorders. This journal is indexed on PubMed Central, the 'PsycINFO' database and CAS, and is the official

Submit your manuscript here: http://www.dovepress.com/neuropsychiatric-disease-and-treatment-journal

\section{Dovepress}

journal of The International Neuropsychiatric Association (INA). The manuscript management system is completely online and includes a very quick and fair peer-review system, which is all easy to use. Visit http://www.dovepress.com/testimonials.php to read real quotes from published authors. 